\title{
Study on the Operation Mechanism of Chinese Private Express Industry
}

\author{
Yanni Li ${ }^{\text {a }}$, Yun Lin, Zaibo Wang, Baichao Gong and Yanling Tang* \\ School of Foreign Languages, Changchun Institute of Technology, Jilin 130012, China; \\ aliyanni2007@163.com
}

Keywords: express, industry, FedEx, operation.

\begin{abstract}
With the development of Chinese economy, China express industry comes to enjoy a boom. Due to the E-commerce, the traditional China Post can't meet the needs of all the customers' needs. However, Chinese private express which is comparatively in a small scaled has faced many problems. This paper analyzes the current situation of Chinese private express enterprise and FedEx's operation philosophy, and provides some feasible strategies to the operation of Chinese express industry.
\end{abstract}

\section{Introduction}

Today, more and more people like shopping on line, and such $\mathrm{B} 2 \mathrm{C}$ and $\mathrm{C} 2 \mathrm{C}$ give the chance for expresses to deliver goods[1]. And with the rapid development of China economy, China express industry comes to enjoy a boom and the traditional China Post can't meet the needs of all customers. It is well known that China is a country with a large number of Internet users and people live in the era of pursuing effectiveness and speed. Obviously, express industry is a promising industry in China or even worldwide.Now some famous international express industries especially four international express giant (FedEx, Ups, DHL and TNT), have poured into China and take up a big part in market.

\section{FedEx in China}

FedEx came to China in 1984, and it initially used a local pick-up and delivery agent to serve the China market. Dissatisfied with its low market share after years of operating in China and convinced that the market would grow rapidly after the country's accession to the WTO, the senior management at FedEx decided to re-examine their long-term marketing strategy in China.

Market target in China. Firstly, the market target is to conquer the big potential market in China. It's important for such international express to dominate the market. Market share is the first target. In recent years, FedEx has done its best to set up its network, hoping to extend its service to every city and standing high in China. According to statistic, FedEx's business scope in 2002 had covered 221 cities. And at that time, it ambitiously planned to spread its flight service in 300 cities. FedEx has completed it, which has surprise other international express companies. And about customer, all companies have advocate "customer orientation". Besides, FedEx still take PSP and SFA as its philosophy to operate the corporation. Their service wins the reputation upon it. Secondly, any company can't survive and develop without resource such as human resource and material resource. Then FedEx has to improve the resource allocation efficiency and utilization efficiency through making sure the supply of resource and the development goal. General speaking, FedEx has to develop its territory. .

Strategy priority in China. After the establishment of the strategic goals, FedEx made its strategic points based on the external environment and internal conditions of the development. Its development in China can be divided into two phases and different phases' strategic focus is different. In the initial phase about more than ten years after entering China, its strategic focus is the introduction of advanced service concept, the practice of high-quality services, laying a solid customer base. FedEx entered China from the very beginning, it focus the development of China's express business as a vital strategic point, which can be seen from its manifestations that it took part in the fierce competition among international express enterprises, Chinese private express enterprises and China Post (EMS). FedEx in 2000 launched a convenient new service to Chinese customers 
--Asia and North America Next Day Arrival. Through this new business, the express of customer who is located in Beijing, Shanghai, Guangzhou, Shenzhen and the surrounding cities can be delivered to 15 Asian cities and major cities in the United States and Canada in the next working day. The fastest EMS express mail in our country also needs two days to deliver. In the express industry which considers time as life, EMS is no doubt getting a shock[2]. FedEx's main actions in China are: opening logistics research centers, technology development center and customer service centers, continuing to nurture new technology advantages and service advantages, strengthening human resources development and training. Relying on its strong leadership in the express business, it has built an extensive firm network. Then FedEx began to actively develop other business in China, such as supply chain integration services.And it of course operates well, which worth express enterprises learning, especially the private express in China.

Strategies of FedEx in China. FedEx's strategies in China can be divided into two parts: market strategy and operating strategy. As for market strategy, FedEx entered China market by joint venture with Datian Group. For many years' development in China, they turned the joint venture into foreign-funded corporation and it took up big market share. In the strategy of business scope, it aims at accomplishing a comprehensive and complete process. Now it has congregated international express, transportation, logistics, e-commerce and supply chain management. Obviously, its special mode wins the core competitive advantage. FedEx is oriented at customers' needs. Besides the service of transportation, storage and distribution, it also provides logistic solutions, logistics system design and more value-added services.

Its operating strategy concentrates on information management, skill service and after-sale service. Its information management system is real-time information system, electronic data exchange system and whole-process tracking system. The online trading software Business Link can help customers integrate online transaction of all links. For example, it can connect custom and ports through EDI system to improve transmission of real-time information. And customers can log on FedEx official websites to track the mails or parcels. FedEx logistics distribution center delivers the goods just in time and in accurate time by reasonable storage and advanced information system. Apart from building up service center and customer information database, FedEx emphasizes the cooperation with customers and provide distribution scheme according to customers' specific requirements. It also offers the free computer equipment and network inquiry software, and then customers can track the delivery at home through internet[3].

Advantages and disadvantages of FedEx. Every company has its own limitation and FedEx also has its own advantages and disadvantages. Each successful business has its secret and a search of FedEx's success is made.

The key success factors are speed, accuracy, traceability, time-definite service, prompt response, reliability, extensive network, relationship management. FedEx is the first and only international express carrier in China to offer money back grantee which give customer a comfortable feeling. It has been the first one to link its network with customs for electronic clearance. Surely it can offer later cut-off time and early deliveries to its time sensitive customers. And it owns innovative transportation, communication and information infrastructure. Besides, its strong presence in the US has won high reputation and its network covering more than 220 countries. As FedEx has expanded its business to China, it should do as the Chinese do. Then it studied the environment in China and realize the importance of having good communications with the China government.

Its disadvantages are high operating cost and government regulations. As an important international express in China, it owns a comparatively perfect transportation facility and supply chain, which would meet most customers' needs. However, it will take high cost, so it is problem cross FedEx's CEO. It is not flexible in China local market compared to the local express. At the same time, it should face the government regulations which protect local interest. Every country would do its best to protect its local interest through protectionism. 


\section{Chinese Private Express Enterprise}

In recent years, Chinese private express enterprise develops quickly with the rise of E-commerce. And some have become comparatively large-scaled such as Shunfen, Shengtong, Zhaijisong, etc. However, problems exist in private express. Policy constraints, small-scaled, little capital, and less-developed operation philosophy are most private expresses' problems. Their structure is not reasonable, the IT backward, capital deficient, staff quality poor. Besides, there is limitation in the policy with it. What is even worse, they don't have standard rule on their service and they have small target market. Obviously, the phenomenon that parcels or mail are missing or destroyed, while they shirk responsibility. Seen from this point, most private express enterprises perform silently without making any promotion and make no effort in giving good expression to customers. Apparently, they lack the proper market positioning, ignore the brand construction, while focus on malignant competition with other express companies[4]. What's more, they neglect the enterprise's internal management and personnel management. So it is a long way for these expresses to go. While at the same time, it is undeniable that private express enterprise is the domestic group with most vitality and growth potential and it's development plays an important in the future of domestic express industry. Then if private expresses want to develop further, they should develop their own advantage and absorb others' experience. FedEx is a good example. But there are a lot of private expresses and each has their own characters. SF is a China leading private express and it is the most successful one compared with other expresses. Although SF hasn't ranked in Fortune 500 as FedEx, it ranked 14 in China Logistic 50 in 2010 according to www.chinawuliu.com. Obviously, it still is a successful express and it has ever been called Chinese FedEx.

\begin{tabular}{|l|l|l|l|l|}
\hline & Market positing & Advantages & Disadvantages & Philosophy \\
\hline $\begin{array}{l}\text { Chiese } \\
\text { Private } \\
\text { Express } \\
\text { Enterprise }\end{array}$ & $\begin{array}{l}\text { Almost intra-city } \\
\text { express, some domestic } \\
\text { express and little }\end{array}$ & $\begin{array}{l}\text { Flexible operation, } \\
\text { Low price, } \\
\text { international express }\end{array}$ & $\begin{array}{l}\text { Fast delivery } \\
\text { Bad service to } \\
\text { Small-scaled, } \\
\text { Little capital }\end{array}$ & $\begin{array}{l}\text { Policy constraints, } \\
\text { some are advanced }\end{array}$ \\
\hline FedEx & Almost international & Abundant financing, & Shortage of China & Advanced, \\
& express, some domestic & Fast delivery, & logistic network, & Concrete \\
& express and little & Sound world & Policy constraints & \\
& intra-city express & network & & \\
\hline
\end{tabular}

Figure 1 Comparison between Chinese private express and FedEx

It is shown from Figure 1 that the market positing is different and each has their major market. Private express enterprise aims at intra-city express because it is small-scaled and it doesn't have enough transportation and IT equipment to support it. They both can serve the service with fast speed. Private express can offer flexible service in low price, while FedEx charges the comparatively high price. But the FedEx's service is better than Chinese private express. The good service will affect customers' satisfaction about the Express. According to Determinants of successful logistical relationships, the staff's attitude to customer plays an important role in customers' satisfaction. FedEx has a complete working code for every staff and its advanced philosophy fulfills staff's mind. The staffs know what they should do. Besides, FedEx owns sound world network with abundant financing. It can offer very good welfare to each staff and in return staff can do their best to work hard. Both private express and FedEx have to face the policy constraints. Each country will protect its state-owned industry. Both would meet the policy constraints. China is a country of high context. So they need to know well about Chinese culture. 


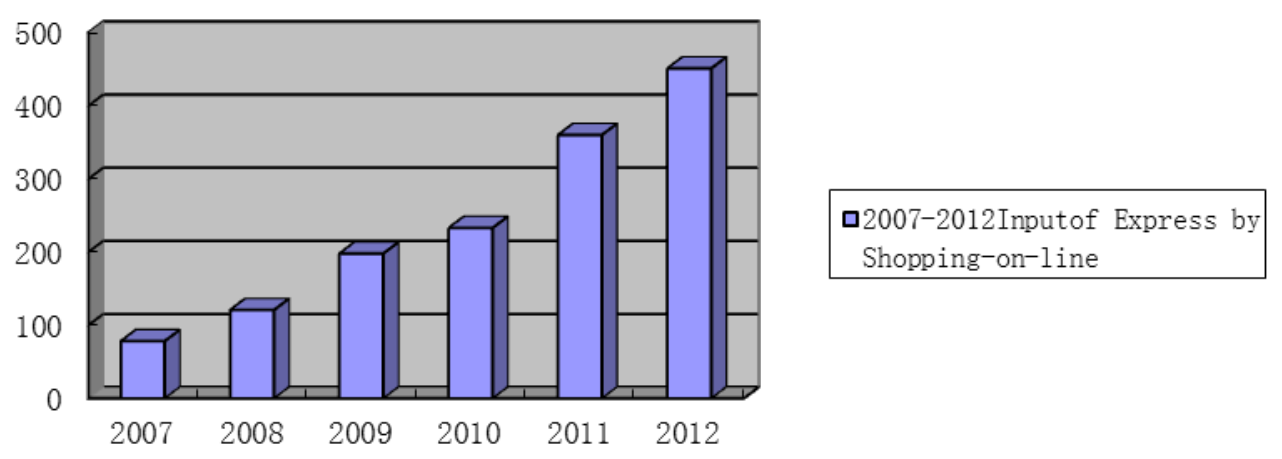

Figure 2 Investment and Prospect of Shopping-on-line from 2010 to 2012

While from Figure 2, it can be seen that E-commerce is a golden chance for express industry, but it has to be admitted that each coin has two sides, and it is necessary to sustain the good and make a progress to improve the bad. Due to its own condition, private express would lead to its own disadvantage. Then if progress need to be made, some fundamental changes are necessary. Firstly it should face the problem that it needs more funds to expand its market and to perfect its transportation facilities. How the funds come from? More profits will bring out funds. And how these profits come out? The company should operate properly. And how properly? It needs the philosophy to guide them. So the proper philosophy is very important for the industry to improve the situation. Secondly, it should work out a plan to deal with policy constraints. In China, facing government policy is an important course that people who deal with something concerned about government. It is also a kind of spiritual exploring. Then it can be seen clearly that strategy for Chinese private express is difficult to work out.

\section{Summary}

Chinese private express enterprise would bring a lot fortune and vitality to the market. Although Chinese private express enterprises now are facing the big challenge in the market, there is still room for them to improve. During the process of their development, they should keep the good and follow the international trend. FedEx owns many advantages, of which Chinese private express can learn from, but application of FedEx's advanced philosophy should be combined with Chinese culture. Some strategies has been mentioned above, such as talent first, customer first and technology first, but they need to be performed properly. And one saying should be kept in mind that where there is a will, there is a way. If private express enterprises make efforts to develop through the right philosophy, they will succeed. What's more, their success would promote the development of other relative industries. With the rapid development of E-commerce, it will be a promising industry in the coming years. Besides, the problems that expresses have made should be solved. Replacement of oil, reduce of noise and optimization of resource allocation should be adopted immediately to protect the environment people live in.

\section{References}

[1]. William Wei Wei Song, Shenghua Xu, Changxuan Wan, Yuansheng Zhong, Gregory Wojtkowski and Henry Linger. Information System Development Asian Experiences. Springer, 2011, o. 35-36.

[2]. Research and Market: China Express Delivery Industry Report.http: www.thefreelibrary.com, 2010

[3]. Boyle Mathew. Why FedEx Is Flying High. Fortune, 2004, p. 10

[4]. Gang Li. Trend analysis of Chinese express industry. Logistics and Management. Vol.32(2010) No.4, p .5-7. 